\title{
Performance Study for Miller Cycle Natural Gas Engine Based on GT-Power
}

\author{
Songsong Song and Hongguang Zhang
}

\begin{abstract}
In order to improve the thermal efficiency of natural gas engine and reduce the $\mathrm{NO}_{\mathrm{x}}$ emission from engine, this paper presented the technical route which applied Miller cycle to turbocharged lean-burn natural gas engine. GT-Power software was used to model the turbocharged natural gas engine, and simulation research based on Miller cycle was performed according to various engine loads in the engine speed range of $2000-5000 \mathrm{rpm}$. The simulation results showed that, under part load (50\% of the engine full load) operating conditions of the turbocharged lean-burn natural gas engine, compared with Otto cycle, Miller cycle can reduce the brake specific fuel consumption (BSFC) and $\mathrm{NO}_{\mathrm{x}}$ emission. Under high load and low speed as well as moderate load and high speed operating conditions, Miller cycle can effectively reduce the BSFC. Under high load and low speed or high speed operating conditions, the $\mathrm{NO}_{\mathrm{x}}$ emission can be reduced apparently.
\end{abstract}

Index Terms-Natural gas engine, simulation, miller cycle.

\section{INTRODUCTION}

With the rapid development of automobile industry, people are paying more and more attention to the automobile emission and environmental problem [1]. The natural gas has many characteristics, such as low emission, rich storage and convenience to use in the city for vehicle. Nowadays, scholars all over the world are studying the natural gas engine. The main objectives of these studies are to investigate the fuel supply, the mixture formation in cylinder, the combustion control and the exhaust treatment. Wang et al. investigated the factors that affect the lean combustion limit of hydrogen-natural gas engine. The results showed that both over-retarded and over-advanced ignition timing would baffle the extension of lean-combustion limit [2].

Ma et al. conducted an experimental research to examine the influence of the air fuel ratio, ignition timing and the oxidation catalyst converter on the emission characteristic. The result showed that NOx emissions increase initially and then decrease, but NMHC emissions decrease initially and increase as the air fuel ratio increases [3]. Li et al. introduced the fuel charge system of natural gas engine, such as intake port injection, direct in-cylinder fuel injection and pre-chamber fuel injection. Through analysis, they found that fuel direct injection could improve the efficiency of air charge and reduce the emission, but their systems' devices are complex and should be more perfected in future

Manuscript received July 1, 2014; revised August 27, 2014.

The authors are with the Beijing University of Technology, Pingleyuan No.100, 100124 Beijing, China (e-mail: qihesong@126.com, zhg5912@263.net).
[4].

However, few attentions have been paid to the working process of the natural gas engine. In this paper, GT-Power software was used to simulate the turbocharged natural gas engine. BSFC and $\mathrm{NO}_{\mathrm{x}}$ emission were analyzed for two kinds of engine working processes based on Otto cycle and Miller cycle respectively.

\section{Methodology}

In order to improve the thermal efficiency of the engine, Ralph Miller proposed Miller cycle in 1947 [5], which is a kind of over-expanded cycle, as shown in Fig. 1.

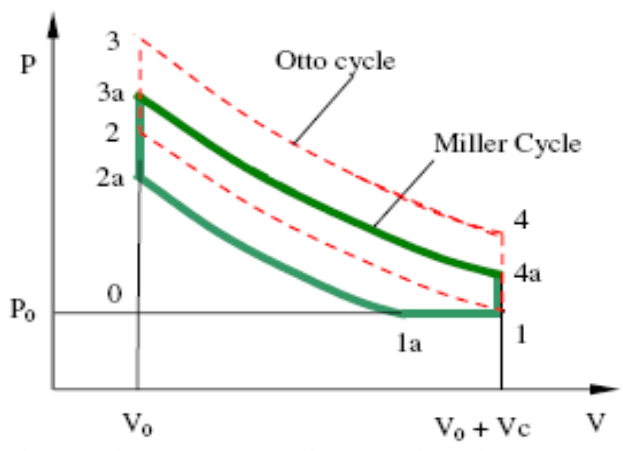

Fig. 1. Indicator diagram of Otto cycle and Miller cycle.

As shown in Fig. 1, compared with Otto cycle, for the same piston stroke, Miller cycle can keep the expansion ratio unchanged, and make compression ratio become smaller than expansion ratio, which helps to improve the thermal efficiency. Therefore, Miller cycle has been actively studied by many scholars [6]-[10].

Miller cycle can be realized by three ways:

1) Early rotary valve closure (ERVC), the rotary valve is installed on the cylinder head between the intake manifold and intake valve.

2) Early intake valve closure (EIVC), namely the intake valve is closed early in the intake stroke.

3) Late intake valve closure (LIVC), some of the air and fuel mixture is blown back to the intake manifold in the intake stroke, and then the effective compression ratio is reduced. This way is shown in Fig. 2.

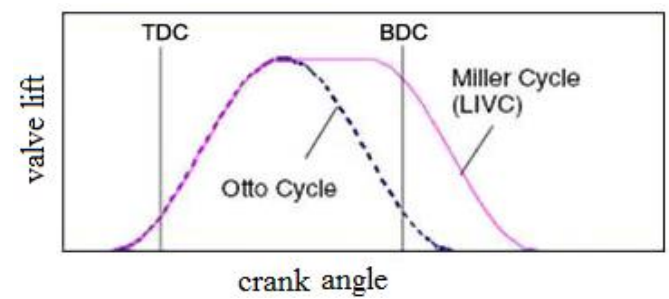

Fig. 2. Valve timing schematic diagram of Miller cycle. 
Miller cycle can be realized by variable valve actuation (VVA), which means that intake valve opening timing and intake valve opening duration can be controlled accurately. This paper adopts this way to realize Miller cycle for the turbocharged lean-burn natural gas engine.

The modified natural gas engine used in this researchis built on the basis of JL465Q5 gasoline engine. Themain technical parameters of the gasoline engine are listed in Table I.

Based on the main technical parameters above, the turbocharged natural gas engine is modeled by using GT-Power software. Furthermore, the parameters of intake and exhaust model, turbocharger model, heat transfer model, fuel injector model and crank train model are set respectively. Fig. 3 shows the simulation model.

In order to ensure that the simulation model can indicate the practical working process of the engine and predict running performance of the engine definitely, the simulation model is validated by using experimental data of the natural gas engine through bench test.

\begin{tabular}{|c|c|}
\hline Parameters & Value \\
\hline Displacement / L & 1.012 \\
\hline Compression ratio & 8.8 \\
\hline Bore / mm & 65.5 \\
\hline Stroke / mm & 74 \\
\hline Rated power/ kW & $39 @ 5300 \mathrm{rpm}$ \\
\hline Maximum torque $/ \mathrm{N} \cdot \mathrm{m}$ & 78 \\
\hline Valve timing & $\begin{array}{l}\text { IVO- } 16^{\circ} \mathrm{BTDC} \\
\mathrm{IVC}-52^{\circ} \mathrm{ABDC} \\
\mathrm{EVO}-54^{\circ} \mathrm{BTDC} \\
\mathrm{EVC}-14^{\circ} \mathrm{ATDC}\end{array}$ \\
\hline
\end{tabular}

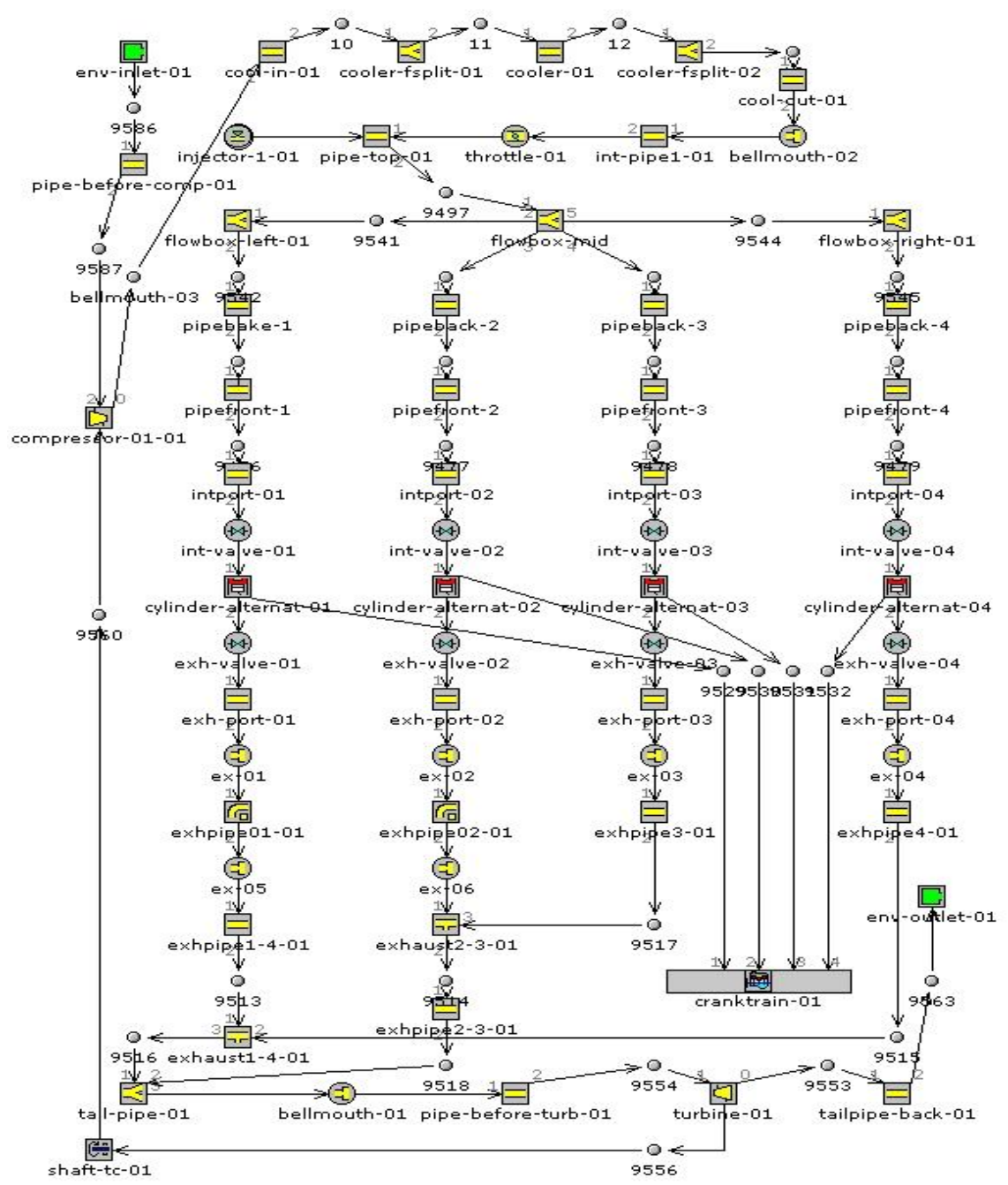

Fig. 3. Simulation model of the turbocharged natural gas engine.

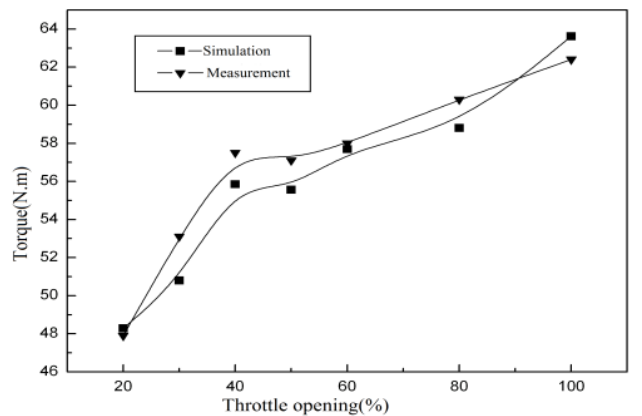

Fig. 4. Engine torque under various loads.
When engine speed is 2000rpm and excess air ratio is 1.0 , under different throttle opening conditions, the simulation and test results of the engine torque are shown in Fig. 4. The simulation results are very close to the test results, the differences between the simulation and the test results are within the range of $5 \%$.

Fig. 5 shows the simulation and test results of power output under the full load operating conditions. The simulation results are very close to the test results, the differences between the simulation and the test results are within the range of $6 \%$. 


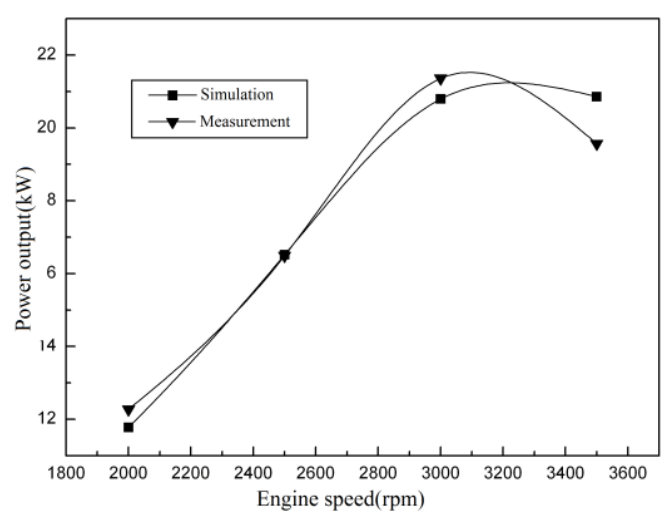

Fig. 5. Engine power output under full load.

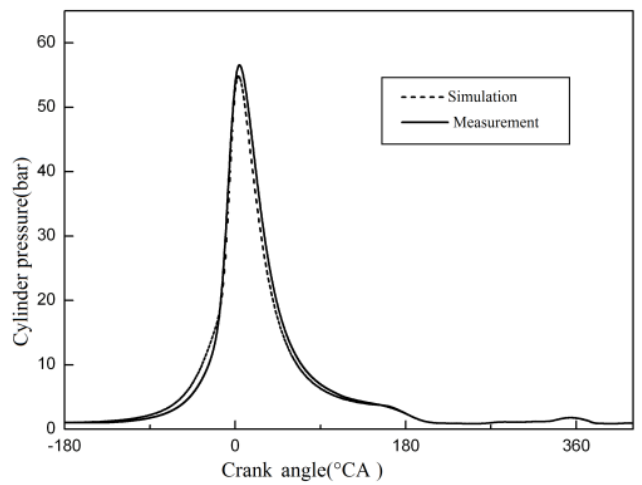

Fig. 6. Cylinder pressure.

When engine speed is 2000rpm, excess air ratio is 1.0 , throttle opening is $40 \%$ and ignition timing is $39^{\circ} \mathrm{CA}$ BTDC, the simulation and test results of the cylinder pressure are shown in Fig. 6. The difference of peak cylinder pressure between the simulation and the test results is within the range of $3 \%$, the difference of the occurrence time of peak cylinder pressure between the simulation and the test results is $1.4^{\circ} \mathrm{CA}$. This shows that the simulation results are very close to the test results.

It is noticed from the above-mentioned analysis that the simulation model is consistent with the actual engine. So the simulation model can be used to analyze the running performances of the turbocharged natural gas engine.

\section{INTERPRETATION OF RESULTS}

By using the simulation model, the running performances of the turbocharged lean-burn natural gas engine based on the Miller cycle and Otto cycle are investigated. Under the part load (50\% of the full load) operating conditions, when engine speed varies in the range of 2000-5000rpm, the power output of the engine using Otto cycle is calculated. Furthermore, on the basis of keeping the intake valve opening timing unchanged and removing the throttle valve, Miller cycle can be realized by means of retarding the intake valve closing timing, aiming to make the power output of Miller cycle same with that of the Otto cycle under the corresponding operating conditions. The running performances for the two kinds of cycles including cylinder pressure, pumping loss, BSFC and $\mathrm{NO}_{\mathrm{x}}$ emission are compared and analyzed.

As we can see from Fig. 7 and Fig. 8, compared with Otto cycle, Miller cycle engine leads to lower BSFC and $\mathrm{NO}_{\mathrm{x}}$ emission for the natural gas engine. Particularly, when engine speed is 2000rpm, the decrease of BSFC reaches up to $5 \mathrm{~g} / \mathrm{kW} \cdot \mathrm{h}$ at most; when the engine speed is $4500 \mathrm{rpm}$, the decrease of $\mathrm{NO}_{\mathrm{x}}$ emission reaches up to $344 \mathrm{ppm}$ at most.

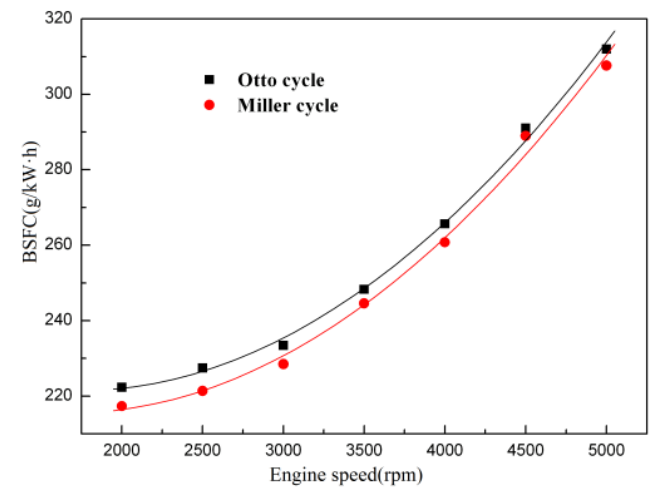

Fig. 7. BSFC for Otto cycle and Miller cycle.

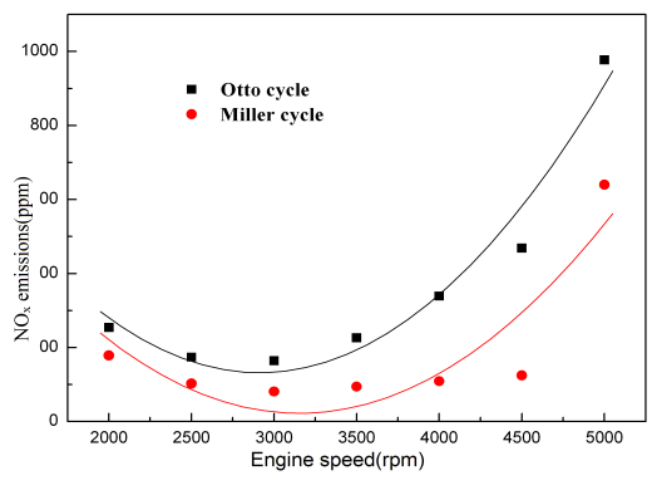

Fig. 8. $\mathrm{NO}_{\mathrm{x}}$ emission for Otto cycle and Miller cycle.

According to Fig. 9 and Fig. 10, it can be seen that Miller cycle based engine has higher effective thermal efficiency and PMEP than Otto cycle based engine. When engine speed is 2000rpm, the increase of effective thermal efficiency reaches up to $0.74 \%$ at most; however, with the increase of engine speed, the increment in effective thermal efficiency gradually decreases. When Miller cycle is applied to the engine and engine speed is not higher than 3000rpm, PMEP value is positive, which means that the in-cylinder gas does positive work on the piston during the scavenging process. When Otto cycle is applied to the engine and engine speed is in the range of 2000-5000rpm, PMEP value is negative, which means that the in-cylinder gas does negative work on the piston during the scavenging process.

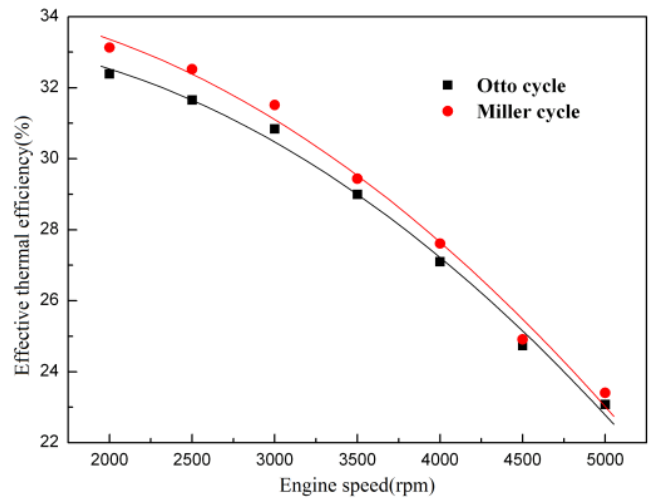

Fig. 9. Effective thermal efficiency for Otto cycle and Miller cycle. 


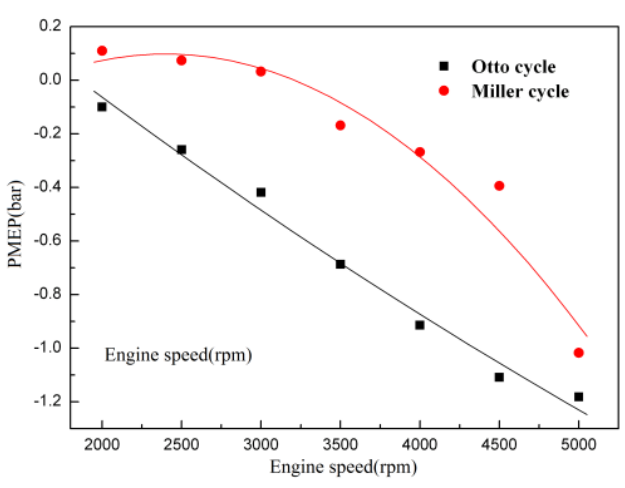

Fig. 10. PMEP for Otto cycle and Miller cycle.

The main reasons for the above-mentioned phenomena are as follows: First, when Miller cycle is applied to the turbocharged lean-burn natural gas engine, because of the retarded closing of intake valve, the effective compression stroke becomes shorter indeed, then the compression ratio becomes lower, consequently, the peak cylinder pressure is lower than that of Otto cycle based engine, which is shown in Fig. 11(a). The lower cylinder pressure is conducive to reducing the friction loss and gas leakage between piston ring and cylinder jacket, as well as decreasing engine roughness. Second, as shown in Fig. 12, when Miller cycle is used, compression ratio decreases, and the peak cylinder temperature decreases, consequently, not only the heat transfer loss but also NOx emission decrease. Third, for Miller cycle's power regulation, throttle valve can be removed, which is benefit for reducing the intake throttling loss and increasing the intake pressure. When engine speed is $2000 \mathrm{rpm}$ and engine power output is $12.3 \mathrm{~kW}$, the indicator diagram for Otto cycle and Miller cycle is shown in Fig. 11. It can be seen from Fig. 11(b), for Miller cycle, the pumping work value is positive; for Otto cycle, the pumping work value is negative.

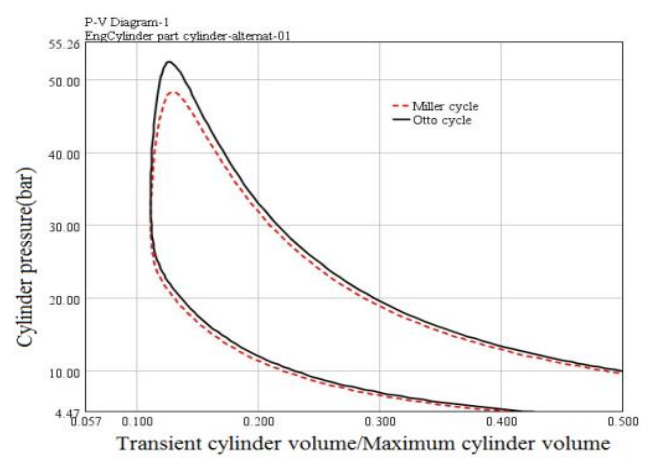

(a) Compression stroke and expansion stroke.

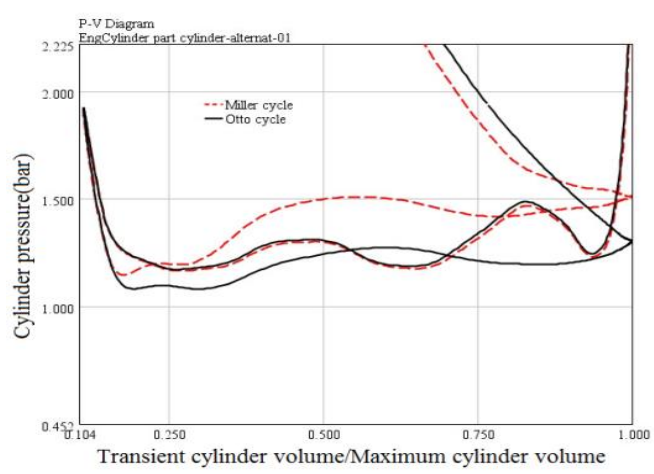

(b) Intake stroke and exhaust stroke.

Fig. 11. Indicator diagram for Otto cycle and Miller cycle.

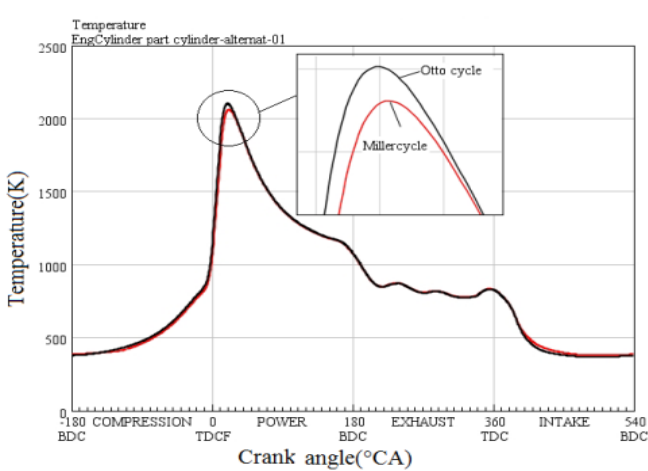

Fig. 12. Cylinder temperature for Otto cycle and Miller cycle.

As have discussed above, under the part load (such as $50 \%$ of the full load) operating conditions, fuel economy and $\mathrm{NO}_{\mathrm{x}}$ emission of the turbocharged lean-burn natural gas engine can be improved by using Miller cycle.

When the excess air ratio is in the range of 1.19-1.44 (namely lean burn condition), engine speed is in the range of 2000-5000rpm, brake mean effective pressure (BMEP) is in the range of 4.64-12.2bar, the running performances of the turbocharged natural gas engine based on Otto cycle and Miller cycle are analyzed. For a certain operating conditions, the two cycles have the same excess air ratio, ignition timing and valve timing, then the compression ratio for Miller cycle is adjusted to making the power output of Miller cycle equal to that of Otto cycle. Furthermore, compared with Otto cycle based engine, the improvement in BSFC and $\mathrm{NO}_{\mathrm{x}}$ emission of Miller cycle based engine is investigated, the simulation results are shown in Fig. 13 and Fig. 14.

Fig. 13 indicates the improvement of BSFC of Miller cycle based engine. It can be seen that BSFC decreases for the majority of engine operating conditions. Especially, under low speed and high load as well as high speed and moderate load operating conditions, BSFC decreases apparently. Under low load and moderate speed as well as low load and high speed operating conditions, BSFC increases slightly. In practice, the engine rarely runs with low load and moderate speed or low load and high speed, so the turbocharged lean-burn natural gas engine based on Miller cycle can improve BSFC for the majority of engine operating conditions.

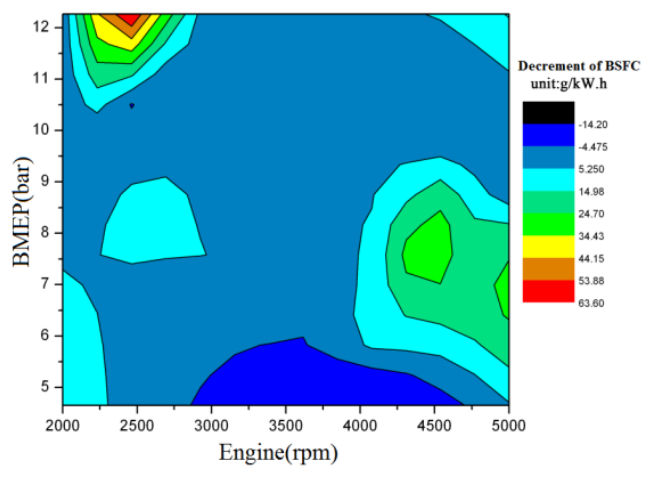

Fig. 13. Improvement in BSFC when Miller cycle is used.

Fig. 14 indicates the improvement of $\mathrm{NO}_{\mathrm{x}}$ emission of Miller cycle based engine. It can be seen that the trend of improvement in $\mathrm{NO}_{\mathrm{x}}$ emission is similar to the trend of improvement in BSFC, when the engine runs with low 
speed and high load or high speed, $\mathrm{NO}_{\mathrm{x}}$ emission decreases apparently.

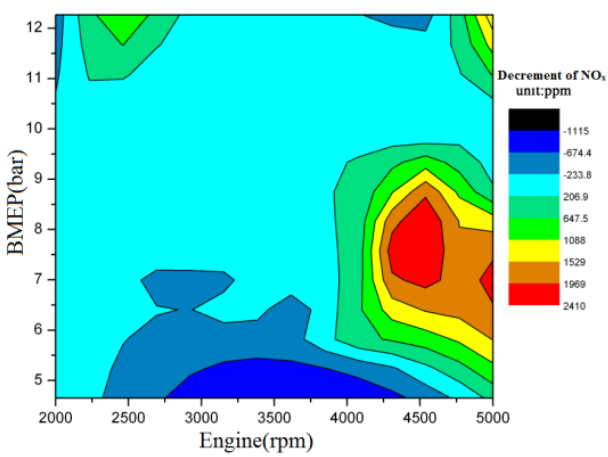

Fig. 14. Improvement in $\mathrm{NO}_{\mathrm{x}}$ emission when Miller cycle is used.

The main reasons for the above-mentioned phenomena are as follows: for turbocharged lean-burn natural gas engine, in order to ensure the enough torque under low speed and high load condition or the higher power output under high speed condition, rich mixture (namely the excess air ratio is lower) is needed, which results in higher cylinder temperature and higher thermal load. According to the aforementioned analysis, by using Miller cycle, peak cylinder pressure and peak cylinder temperature can decrease to some extent, friction loss and heat transfer loss decrease. On the other hand, because of retarded closing of intake valve in the compression stroke, the cylinder can be cooled by the fresh charge. Therefore, Miller cycle is benefit for reducing $\mathrm{BSFC}$ and $\mathrm{NO}_{\mathrm{x}}$ emission under high load and low speed operating conditions as well as high speed operating conditions.

\section{CONCLUSIONS}

1) Compared with Otto cycle, BSFC and $\mathrm{NO}_{\mathrm{x}}$ emission of turbocharged lean-burn natural gas engine decrease by using Miller cycle under part load operating conditions.

2) For the majority of engine operating conditions, by using Miller cycle, BSFC and $\mathrm{NO}_{\mathrm{x}}$ emission decrease. Especially, under low speed and high load as well as high speed and moderate load operating conditions, BSFC decreases apparently. The trend of improvement in $\mathrm{NO}_{\mathrm{x}}$ emission is similar to the trend of improvement in BSFC, when the engine runs with low speed and high load or high speed, $\mathrm{NO}_{\mathrm{x}}$ emission decreases apparently.

3) For the same engine power output, turbocharged lean-burn natural gas engine based on Miller cycle has the better fuel economy and emission performance.

\section{ACKNOWLEDGMENTS}

This work was sponsored by the National Natural Science Foundation of China (Grant No. 51376011), Scientific Research Key Program of Beijing Municipal Commission of Education (Grant No. KZ201410005003), and the Twelfth Scientific research Foundation for graduate students in Beijing University of Techonlogy (Grant No. ykj-2013-9302; Grant No. ykj-2013-9386).

\section{REFERENCES}

[1] Research group of the CCP party school, "Study on the development strategy of China's new energy," Review of Economic Research, vol. 52, pp. 2-30, 2011

[2] X. Wang, H. G. Zhang, B. F. Yao et al., "Experimental study on the factors affecting lean combustion limit of S. I engine fueled with compressed natural gas and hydrogen blends," Energy, vol. 38, issue 1 , pp. 58-65, 2012

[3] F. H. Ma, J. J. Wang, W. Chen et al. "Emission Characteristic of Turbocharged Lean Burn CNG Engine," Chinese Internal Combustion Engine Engineering, vol. 29, no. 2, pp. 10-14, 2008.

[4] S. Z. Li, W.G. Zhang, and Z. Huang, "Research on fuel charge system of natural gas engine," Transactions of the Chinese Society for Agricultural Machinery, vol. 36, no. 2, pp. 127-130, 2005.

[5] Y. Zhao and J. Chen, "Performance analysis of an irreversible miller heat engine and its optimum criteria," Applied Thermal Engineering, vol. 27, no. 4, pp. 2051-2058, 2007.

[6] A. Al-Sarkhi, J. O. Jaber, and S. D. Probert, "Efficiency of a miller engine," Applied Energy, vol. 83, no. 4, pp. 343-351, 2006.

[7] R. Mikalsen, Y. D. Wang, and A. P. Roskilly, "A comparison of Miller and Otto cycle natural gas engines for small scale CHP applications," Applied Energy, vol. 86, no. 6, pp. 922-927, 2009.

[8] C. Wu, P. V. Puzinauskas, and J. S. Tsai, "Performance analysis and optimization of a supercharged miller cycle otto engine," Applied Thermal Engineering, vol. 23, no. 5, pp. 511-521, 2003.

[9] Y. D. Wang, L. Lin, A. P. Roskilly, S. C. Zeng, J. C. Huang et al., "An analytic study of applying miller cycle to reduce NOx emission from petrol engine," Applied Thermal Engineering, vol. 27, no. 11, pp. 1779-1789, 2007.

[10] H. Endo, K. Tanaka, Y. Kakuhama et al., "Development of the Lean Burn Miller Cycle Gas Engine," in Proc. 5th International Symposium on Diagnostics and Modeling of Combustion in Internal Combustion Engines, Nagoya, July 1-4, 2001.

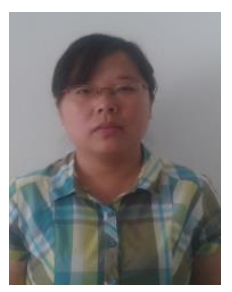

Songsong Song was born in China on December 6, 1982. Now she is a post-graduate student at Beijing University of Technology. Her research interests include waste heat recovery and organic Rankine cycle.

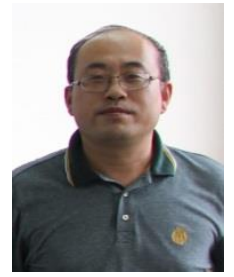

Hongguang Zhang was born in China on February 21,1970 . He got his bachelor's degree, the master degree and doctor degree from Beijing Institute of Technology, China, in 1992, 1995, and 1998 respectively. From 1998 to 2000, he worked in the Institute of Engineering Thermophysics, Chinese Academy of Sciences as a post doctor. Later he taught at Beijing University of Technology. His research interests include combustion control and energy conservation of internal combustion engine. 